\title{
On the implementation of faults in finite-element glacial isostatic adjustment models
}

\author{
Rebekka Steffen $^{\mathrm{a}, *}$, Patrick Wu ${ }^{\mathrm{a}}$, Holger Steffen ${ }^{\mathrm{a}, \mathrm{b}}$, \\ David W. Eaton ${ }^{a}$ \\ ${ }^{a}$ Department of Geoscience, University of Calgary, 2500 University Drive NW, Calgary, \\ Alberta, T2N 1N4, Canada \\ ${ }^{\mathrm{b}}$ now at: Lantmäteriet, Lantmäterigatan $2 c, 80182$ Gävle, Sweden
}

\begin{abstract}
Stresses induced in the crust and mantle by continental-scale ice sheets during glaciation has triggered earthquakes along pre-existing faults, commencing near the end of the deglaciation. In order to get a better understanding of the relationship between glacial loading/unloading and fault movement due to the spatio-temporal evolution of stresses, a commonly used model for glacial isostatic adjustment (GIA) is extended by including a fault structure. Solving this problem is enabled by development of a workflow involving three cascaded finite-element simulations. Each step has identical lithospheric and mantle structure and properties, but evolving stress conditions along the fault.

The purpose of the first simulation is to compute the spatio-temporal evolution of rebound stress when the fault is tied together. An ice load with a parabolic profile and simple ice history is applied to represent glacial loading of the Laurentide Ice Sheet. The results of the first step describes the evolution of the stress and displacement induced by the rebound process. The second step in the procedure augments the results of the first, by computing the spatio-temporal evolution of total stress (i. e. rebound stress plus tectonic background
\end{abstract}


stress and overburden pressure) and displacement with reaction forces that can hold the model in equilibrium. The background stress is estimated by assuming that the fault is in frictional equilibrium before glaciation. The third steps simulates fault movement induced by the spatio-temporal evolution of total stress by evaluating fault stability in a subroutine. If the fault remains stable, no movement occurs; in case of fault instability, the fault displacement is computed.

We show an example of fault motion along a $45^{\circ}$-dipping fault at the ice-sheet centre for a two-dimensional model. Stable conditions along the fault are found during glaciation and the initial part of deglaciation. Before deglaciation ends, the fault starts to move, and fault offsets of up to $22 \mathrm{~m}$ are obtained. A fault scarp at the surface of $19.74 \mathrm{~m}$ is determined. The fault is stable in the following time steps with a high stress accumulation at the fault tip. Along the upper part of the fault, GIA stresses are released in one earthquake.

Key words: Glacial isostatic adjustment; Fault; Finite element modelling; Flexural stresses; ABAQUS

* Corresponding author.

Email address: rsteffen@ucalgary.ca (Rebekka Steffen). 


\section{$1 \quad 1$ Introduction}

2 In the Earth's crust, stress can be subdivided into tectonic background stress, over-

3 burden pressure, and pore-fluid pressure. The superposition of the first two and the

4 variation of the third part are factors in controlling movement along faults [e.g.

5 Twiss \& Moores, 2007]. Furthermore, stresses due to sedimentation and erosion

6 contribute to the total stress field. In deglaciated regions, an additional stress must

7 be considered: the rebound stress, which is related to rebounding of the crust and

8 mantle after deglaciation [e. g. Wu \& Hasegawa, 1996a, Wu, 1996].

9 During the growth of a continental ice sheet, the lithosphere under the ice load is

10

deformed into the mantle and the removal of the ice load during deglaciation initiates a rebound process. The uplift is well known in formerly glaciated areas, e.g. North America and Scandinavia, and in currently deglaciating areas, e.g. Alaska, Antarctica, and Greenland. The whole process of subsiding and uplifting during the growth and melting of an ice load and all related phenomena is known as glacial isostatic adjustment (GIA).

During the process of glaciation, the surface of the lithosphere is depressed underneath the ice load and compressional flexural stresses are induced in the upper lithosphere, whereas the bottom of the lithosphere experiences tensional flexural stresses [e. g. Adams, 1989a, Wu \& Hasegawa, 1996a]. An additional vertical stress due to the ice load is present, which decreases to zero during deglaciation [e. g. Wu \& Hasegawa, 1996a]. During rebound, flexural stresses relax slowly. These stresses are able to change the original stress directions and regime [Wu, 1996].

In a thrusting background stress regime with the maximum principal stress in the horizontal direction and the minimum principal stress in the vertical direction, the stresses of flexure and vertical loading lead to stable conditions along a fault dur- 
ing loading [Johnston, 1987], and unstable conditions during deglaciation and afterwards [Wu \& Hasegawa, 1996a,b]. This stress regime is dominant in formerly glaciated continental areas; however, in some areas normal or strike-slip regimes occur [e.g. Adams, 1989b, Wu, 1996, 1997, Heidbach et al., 2008, Lund et al., 2009, Mazzotti \& Townend, 2010, Steffen \& Wu, 2011, Steffen et al., 2012].

In the presence of ice, the vertical load increases the minimum principal stress, but horizontal stress (maximum principal stress) is also increased due to flexure. After glacial maximum, the mass of the ice load decreases and the vertical stress induced by this load decreases to zero at the end of the deglaciation. But at this time point, the flexural stress in the horizontal direction still exceeds the initial state, leaving an additional stress in the crust that is able to reactivate a pre-existing fault structure [Wu \& Hasegawa, 1996a].

Several faults with high fault scarps, which document the occurrence of large earthquakes during and after the end of deglaciation, have been identified in North America and Europe [e.g. Kujansuu, 1964, Lagerbäck, 1978, Olesen, 1988, Dyke et al., 1991]. Field investigations indicate that post-glacial unloading and rebound led to the formation or re-activation of faults in continental shields [e.g. Lagerbäck, 1978, Adams, 1989a]. Furthermore, a formerly glaciated area is $\_$generally characterized by moderate seismic activity today.

During the last 15 years, various numerical models have been developed to simulate the occurrence of earthquakes during the glacial period. Of these, two different types of models exist to investigate fault stability. The first type has been employed by Wu [1996, 1997], Wu \& Hasegawa [1996a,b], Johnston et al. [1998], Klemann \& Wolf [1998], Lund [2005] and Lund et al. [2009] using either the finite-element methodology (FEM) or spectral method. These models are based on general GIA models including crust and mantle; they have no explicit fault structure, but con- 
sidered instead virtual faults, which have no effect on the surrounding stress or displacement. This approach is normally used to analyse the isostatic adjustment process in a viscoelastic Earth, in which the lateral boundaries do not have any plate velocity applied. Stress changes and stability of pre-existing faults are evaluated at assumed fault locations [Wu \& Hasegawa, 1996a]. Since, fault surfaces are not included in these models, the estimation of the total stress is made after the modelling of GIA (see Section 2). Therefore, it is not possible to obtain fault slip values with these types of models without modifications.

The rebound stress obtained from these models is combined with the horizontal and vertical background stresses, which are taken into account in the computation of fault stability. Assuming a thrusting tectonic background stress regime, the area below an ice sheet tends to be stable during glaciation and deglaciation, but becomes unstable immediately after the end of deglaciation [Wu \& Hasegawa, 1996a]. Conversely, faults in a normal or strike-slip regime are stable after deglaciation, but may be unstable during glaciation [Wu \& Hasegawa, 1996a]. A comparison of the present day stress orientation in northeastern Canada inferred from focal mechanism data with predictions from this class of GIA models exhibits large differences indicating that these GIA models do not adequately capture stress changes due to local fault zones [see Steffen et al., 2012].

The second type of GIA induced faulting models was developed by Hetzel \& Hampel [2005], Hampel \& Hetzel [2006] and Hampel et al. [2009]. These models include a real fault, but only consist of a lithospheric layer that has horizontal plate velocities prescribed at the lateral boundaries. However, the process of glaciation and deglaciation depends not only on the lithosphere but also on the underlying mantle. Therefore, the inclusion of a deeper mantle in the models is necessary to obtain correct displacement and stress values for the GIA process. Thus, although a 
fault is already included in these models, fault movement is partially driven by the horizontal plate velocities and rebound stress is not completely taken into account.

The results by Hampel et al. [2009] show stable conditions along the fault during glaciation for a thrusting regime. During and after the end of deglaciation the fault starts to move.

In general, both type of models yield similar results. However, the former models do not include an explicit fault, while the latter models do not include the influence of the deeper mantle or rebound stress. Therefore, both models provide only an approximate representation of fault movement in formerly glaciated areas.

In this study, we will present a new two-dimensional (2D) model based on the ABAQUS FEM [Hibbitt et al., 2011], which combines the aforementioned model types by using a defined fault in a general GIA model. The purpose of this paper is to present a new approach, which allows the estimation of fault slip and activation time under realistic rebound conditions. As this is a preliminary investigation, it is not our goal to match modelled results to observed data; consequently detailed earth and ice models are not considered. Rather, our aim is to extend and adapt existing GIA models for fault slip estimation.

The theoretical background of fault stability and the application of FEM for GIA purposes is discussed in the following two sections. In the fourth section, the model setup is summarized. This is followed by results for a simple example that includes a fault.

\section{Stress analysis}

In order to evaluate the stability of a fault in a GIA model we need to model the spatio-temporal evolution of the stress. The state of stress in a region is described 
by the magnitude of vertical and horizontal stresses, and in an area affected by GIA, this consists of the overburden pressure, tectonic background stress, and a rebound component to be determined by the model.

\subsection{Fault stability}

In a stable crust, where no faults exist, rebound stresses are not large enough to fracture rocks and generate earthquakes [e.g. Quinlan, 1984]. However, the crust is not always in a stable state, because it is interspersed with fractures and faults that constitute zones of weaknesses [e.g. Twiss \& Moores, 2007]. The stress conditions in weak but stable, zones in a rock mass can be represented by using a Mohr diagram (Fig. 1).

\section{Figure 1}

The line of failure (black and red lines in Fig. 1) gives information about the stability and frictional behaviour of a fault or rock mass, and relates the shear stress $\tau$ to the normal stress $\sigma_{n}$. The difference in shear stress between line of failure and Mohr circle is used to estimate the stability of the crust or a fault, which is known as the Coulomb Failure Stress $(C F S)$ [Harris, 1998]. The $C F S$ at a specific normal stress $\sigma_{n}$ is defined as:

$$
\begin{aligned}
C F S & =\tau-\tau^{\prime}, \\
& =\tau-\left(\mu\left(\sigma_{n}-P_{f}\right)+C\right), \\
& =\frac{\sigma_{1}-\sigma_{3}}{2}|\sin 2 \Theta|-\mu\left(\frac{\sigma_{1}+\sigma_{3}}{2}+\frac{\sigma_{1}-\sigma_{3}}{2} \cos 2 \Theta\right)+\mu P_{f}-C, \\
& =\frac{\sigma_{1}-\sigma_{3}}{2}(|\sin 2 \Theta|-\mu \cos 2 \Theta)-\mu \frac{\sigma_{1}+\sigma_{3}}{2}+\mu P_{f}-C
\end{aligned}
$$

In equation (1), negative $C F S$ values indicate stable conditions and a change to pos- 
itive values refers to a change from stability to instability along the fault, creating a state where earthquakes may occur.

The $C F S$ depends on the maximum $\left(\sigma_{1}\right)$ and minimum $\left(\sigma_{3}\right)$ principal stresses, an angle $\Theta$, which is related to the angle of the fault $\alpha$, coefficient of friction $\mu$, cohesion $C$, and pore-fluid pressure $P_{f}$ (see below).

The angle $\Theta$ in equation (1) is related to $\alpha$ [Twiss \& Moores, 2007]:

$$
2 \Theta=180^{\circ}-2 \alpha-\arctan \left(\frac{2 S_{13}}{S_{11}+S_{33}}\right),
$$

with $S_{i j}(\{i, j\}=\{1,3\})$ as the components of the stress tensor. The last term in this equation depends on the stress regime and describes the change of $\sigma_{1}$ with respect to the horizontal or vertical direction. In an undisturbed thrust/reverse or normal stress state, with $\sigma_{1}$ and $\sigma_{3}$ being horizontal and/or vertical, the shear stress component $S_{13}$ is zero, and equation (2) becomes $2 \Theta=180^{\circ}-2 \alpha$.

\subsection{Overburden pressure}

The overburden pressure is the weight of the overlying rocks. It depends upon on the gravity $g_{\text {layer }}$ and density $\rho_{\text {layer }}$ of the rocks lying above a depth $z$. Furthermore, the effect of fluid-filled pore spaces $\left(P_{f}\right)$ in the rock contributes to the overburden pressure. The overburden pressure is described by [Twiss \& Moores, 2007]:

$$
S_{V}=\int \rho_{\text {layer }} g_{\text {layer }} d z-P_{f}=\int\left(1-\lambda_{f}\right) \rho_{\text {layer }} g_{\text {layer }} d z
$$

with $\lambda_{f}$ as the ratio of fluid to rock density and is the same for all tectonic background regimes. This equation involves the assumption that the pore pressure is a linear function of the overburden pressure. 
The tectonic background stress includes both the maximum horizontal background stress $\left(S_{H}\right)$ and the minimum horizontal background stress $\left(S_{h}\right)$. The latter can be similar in magnitude to the former, but might differ by several MPa depending on the tectonic environment.

In several studies, the maximum horizontal background stress is calculated assuming that the fault was at frictional equilibrium before the onset of glacial cycles. Although, not all faults are optimally orientated [Abers, 2009]; the stress conditions generally assumed are for optimally orientated faults. For example, glacially induced faults (GIFs) generally have high angles of $50^{\circ}$ to $80^{\circ}$ [Fenton, 1994, Juhlin et al., 2009, Brandes et al., 2012]. They are often assumed to have been active as normal faults before being reactivated as thrust faults [e. g. Adams, 1989a]. As steep dipping faults are not optimally orientated in a thrusting regime, the assumption of optimally orientated faults in such regions is not generally applicable and the horizontal background stress may depend on the fault angle. Thus, an equation for a generally oriented (including non-optimally oriented) fault at frictional equilibrium is needed.

To obtain an equation for every fault angle, several assumptions have to be made. A rock mass with no fractures has a higher cohesion than pre-existing faults [Lanaro et al., 2006]. Furthermore, if no optimally orientated fault exists in this rock mass or has a higher cohesion, other faults with different angles might be reactivated [e. g. Abers, 2009]. To estimate the necessary amount of tectonic background stress to allow slip along non-optimally orientated faults, the fault is assumed to be in frictional equilibrium for all depths in the absence of any ice loads.

The $C F S$ is used to estimate the maximum horizontal component $S_{H}$ of the stress 
in a thrusting regime:

$$
S_{H}=\frac{S_{V}[\mu-\mu \cos 2 \Theta+|\sin 2 \Theta|]+2 C F S^{B G}-2 \mu P_{f}+2 C}{-[\mu \cos 2 \Theta+\mu-|\sin 2 \Theta|]},
$$

where $C F S^{B G}$ denotes the stability of the fault or rock mass before glaciation.

For an optimally orientated fault angle, equation (4) reduces to the same equation as used commonly (e.g. Zoback \& Townend [2001]). Furthermore, equation (4) is only valid along the fault plane. As no other constraints are given for the tectonic background stress in the crust in absence of faults, equation (4) is assumed to be applicable to other parts of the critically stressed crust [Zoback \& Townend, 2001]. The assumption of large magnitudes for the tectonic background stress is one scenario allowing non-optimally orientated faults to break. Other time-dependant changes in the pore-fluid pressure or cohesion are possible. However, neither of the latter scenarios can be realized in our FE model, as cohesion cannot be defined for a fault surface in ABAQUS, and the change in pore-fluid pressure with time due to glaciation and deglaciation is insufficiently studied.

\subsection{GIA stress obtained from ABAQUS}

Several methods have been developed to model the process of GIA [see Steffen \& Wu, 2011, for a review]. Each method has its own advantages and disadvantages, but in general, all methods give reasonably similar results [Spada et al., 2011]. The FEM has become more popular because it can take into account non-linear rheology [Wu, 1999, van der Wal et al., 2010] and lateral heterogeneities such as lateral viscosity [Wang \& Wu, 2006, Wu et al., 2013] and density variations [Ni \& $\mathrm{Wu}, 1998$, Schmidt et al., 2012]. Our methodology is based on the approach by $\mathrm{Wu}$ [2004]. 
In commercial FE packages [e.g. ABAQUS; Hibbitt et al., 2011] the equation of motion,

$$
\nabla \cdot S=0
$$

is solved with $S$ as the stress tensor. However, this equation is not applicable to geophysical problems involving elastic deformation of long wavelengths [Cathles, 1975, Wu, 1992, 2004]. If inertial force, self-gravitation, and internal buyoancies are neglected, the momentum equation in geophysical applications for a flat Earth is of the form [Wu, 2004]:

$$
\nabla \cdot \boldsymbol{S}^{\boldsymbol{G I \boldsymbol { A }}}-\rho_{0} g_{0} \nabla u_{z}=0,
$$

where $\rho_{0}$ and $g_{0}$ represent the density and gravity for the initial background state, and $u_{z}$ is the vertical component of the displacement vector. The last term represents the advection of pre-stress, which means that the initial stress state is carried along with the particle as deformation proceeds [Wu, 2004]. The momentum equation is valid for material compressibility as the buoyancy effect is neglected [Klemann et al., 2003, Bängtsson \& Lund, 2008].

The difference between equation (5) and equation (6) has to be solved, when using commercial FE packages for GIA analyses. It was shown by Wu [2004], that the creation of a new stress tensor $S^{F E}$ is necessary:

$$
\boldsymbol{S}^{\boldsymbol{F E}}=\boldsymbol{S}^{\boldsymbol{G I A}}-\rho_{0} g_{0} u_{z} \boldsymbol{I}
$$

where $\boldsymbol{I}$ denotes the identity matrix. The product of vertical displacement and the identity matrix in the second term of equation (7) changes to the gradient of the vertical displacement by application of the divergence operator. Equation (6) can be rewritten as

$$
\nabla \cdot \boldsymbol{S}^{\boldsymbol{F E}}=0
$$


which is identical to equation (5)

Stress obtained from FE models $\left(\boldsymbol{S}^{\boldsymbol{F} E}\right.$ ) can then be modified to a GIA stress using

$$
\boldsymbol{S}^{\boldsymbol{G I A}}=\boldsymbol{S}^{\boldsymbol{F E}}+\rho_{0} g_{0} u_{z} \boldsymbol{I}
$$

Only the diagonal components of the stress tensor are modified, whereas the shear stress components from the FE model are not changed.

The transformation of the stress and the basic equation of motion provide several boundary conditions, which are summarized in $\mathrm{Wu}$ [2004]. However, the displacement is not affected by the transformation. The method has already been applied in several studies, e.g. Wu [1992, 1996, 1997], Wu \& Hasegawa [1996a,b], Lund [2005], Wu [2009], Brandes et al. [2012], and Schmidt et al. [2012].

The total stress is then estimated as the combination of rebound stress determined by the GIA model and background stress. The stress tensor in ABAQUS ( $\boldsymbol{S}^{\boldsymbol{F} \boldsymbol{E}}$ ) consists of the three diagonal elements $S_{11}^{F E}, S_{22}^{F E}$, and $S_{33}^{F E}$, while the shear stress elements depend on the dimension of the model. In a 2D model, only one additional stress $S_{12}^{F E}$ is required, whereas in a 3D model all three shear stress components $\left(S_{12}^{F E}, S_{13}^{F E}\right.$, and $\left.S_{23}^{F E}\right)$ are used.

The stress in the model is initiated by the command "*initial conditions, type=stress, unbalanced stress=step", which is followed by the number of an element and its corresponding stress values (defined below): Element-Number, $S_{11}^{F E, \text { mod }}, S_{22}^{F E, \text { mod }}, S_{33}^{F E, \text { mod }}, S_{12}^{F E, \text { mod }}, S_{13}^{F E, \text { mod }}, S_{23}^{F E, \text { mod }}$. This line is repeated for 
all elements, where a stress tensor is defined:

$$
\begin{aligned}
& S_{11}^{F E, \text { mod }}=-\left(-\left(S_{11}^{F E}+\left(\rho_{\text {layer }} g_{\text {layer }} u_{z}\right)\right)+S_{H}\right), \\
& S_{22}^{F E, \text { mod }}=-\left(-\left(S_{22}^{F E}+\left(\rho_{\text {layer }} g_{\text {layer }} u_{z}\right)\right)+S_{V}\right), \\
& S_{33}^{F E, \text { mod }}=-\left(-\left(S_{33}^{F E}+\left(\rho_{\text {layer }} g_{\text {layer }} u_{z}\right)\right)+S_{h}\right), \\
& S_{12}^{F E, \text { mod }}=-\left(-S_{12}^{F E}\right), \\
& S_{13}^{F E, \text { mod }}=-\left(-S_{13}^{F E}\right), \\
& S_{23}^{F E, \text { mod }}=-\left(-S_{23}^{F E}\right) .
\end{aligned}
$$

The first term on the right side of equations (10) to (15) is the stress due to an ice load obtained from a GIA model in ABAQUS, without any modifications. The second term on the right side of equations (10) to (12) is needed to convert the output from ABAQUS to rebound stress (after equation (9)), and depends on density and gravity of the layers, and the vertical displacement from ABAQUS. The third term in equations (10) - (12) is the background stress. The third normal stress tensor component $\left(S_{33}^{F E}\right)$ has no effect on the fault movement in a 2D model. Furthermore, the shear stress components $S_{12}^{F E}, S_{13}^{F E, \text { mod }}$ and $S_{23}^{F E, \text { mod }}$ are not changed by the GIA transformation and background stress components.

Stress values obtained and used by ABAQUS are negative for compressional conditions and positive for tensional regimes. In contrast, the geologic sign convention typically prescribes compressional stresses with a positive sign and tensional stresses are negative. To combine both of these sign conventions, the GIA stress $S^{G I A}$ is multiplied by -1 , which results in positive stresses, and the horizontal background stress or overburden pressure are added, which are positive. The obtained positive total stress is used in fault stability calculations. 
Our goal is to develop a model that simulates the GIA process and releases stress along faults. The implementation of an open fault contact in GIA models alters the estimates of GIA stress distribution and evolution. Therefore, it is useful to create a second model to capture the total stress and generate reaction forces. The stresses and the reaction forces are input to a third model where the fault is opened and the slip and the associated changes in stress are modelled. An inclusion of an open fault contact into the GIA model directly is not possible due to the differences in solving of the equation of motion between ABAQUS and GIA. Therefore, a cascaded three part workflow has to be created (Fig. 2), where all models have the same layers, material properties, elements, nodes, foundations, and boundary conditions. The sides of all models are fixed in the horizontal direction, and no velocities are applied.

In ABAQUS, a fault surface is defined by element faces acting upon each other, whereas the element faces on opposite sides are defined by different nodes with the same coordinates. One fault surface should consist of at least two elements on each side of the fault. A fault is included in all three models; however, the fault is not allowed to move in the first and second model. Here, the fault surface is tied together, and no movement can occur. In the third model, the fault surface is open and surface parameters are defined. The coefficient of friction $\mu$ is assigned a value based on static friction and is the only surface parameter used in this study. The cohesion cannot be defined between two fault surfaces and is thus neglected. All fault commands are only allowed to be included in the model setup of an ABAQUS input file. Fault commands in the step procedure cannot be used; therefore, if the behaviour of the fault is changed, a new model must be created. 
The methodology of including a fault into a GIA model is described in more detail below and is depicted in Fig. 2:

[1] The first model (model 1) follows the commonly used GIA models [e. g. Wu \& Hasegawa, 1996a, Lund, 2005]. The earth model, consisting of a lithosphere and underlying mantle, is loaded by an ice model. In this study only one glacial cycle is used. The displacement and stress tensor components are computed for all times during glacial loading and unloading and results are written to an output file at the end of each time point. At this point, model 1 itself is in quasi-static equilibrium. The fault surface is tied together so that no movement can occur (definition in ABAQUS in this study: $*$ Tie, name=faultgia, adjust=yes, type=SURFACE TO SURFACE). The complete model 1 is run before the next step is used. At this point it is possible to use any kind of GIA model, as only the output is used further and an open fault contact is not included. Therefore, there is no feedback from a stress and displacement change due to fault slip to the GIA model.

[2] The output of model 1 is extracted for each time point, and the full stress tensor is calculated following equations (10) to (15). The new stress field is used to evaluate the stability at each element. The fault stability is then calculated as the mean value between all elements acting against each other along the fault surface. If $C F S$ along this fault is positive, a second and third model (model 2 and 3) are created. A negative fault stability indicates stable conditions, and the output from the next time point is evaluated (see step [7]). The evolution of fault stability also includes the stress changes that occurred due to any fault slip. 
[3] Model 2 consists of the same material and layer properties as model 1, and the fault is still tied. This model is created for each time point obtained from model 1 for which a positive CFS is obtained. No ice load is applied, and the displacement from model 1 is used to define new nodal coordinates. The other output parameter, the stress tensor, is changed to a total stress as calculated in the analysis of the fault stability (see step [2]), which is implemented as an initial condition. Consequently, the model is not in equilibrium.

[4] The coordinates of the nodes and the stress variables of the elements are not allowed to change in model 2 . However, the combination of new nodal coordinates and new initial stress conditions leads to unstable conditions as the total stress of GIA and background stress are now included. The simulation of stable conditions due to the fixed movement leads to the creation of reaction forces by ABAQUS, which are acting at each node to compensate for the (additional) stress in the elements and the changed nodal coordinates. In other words, ABAQUS adjusts the stress automatically, which may be appropriate in engineering studies but might lead to false results for this application. As not only the stress is included, but also the change in the nodal coordinates, the reaction forces are not the opposite of the stress values. The reaction forces applied at each node to maintain equilibrium are written to the output and are used in model 3.

[5] In model 3 the same layer and material properties, initial stress conditions, and nodal coordinates as in model 2 are used. As in model 1, the sides of model 3 are not allowed to move in the horizontal direction. Furthermore, the fault is opened (definition in ABAQUS in this study: *Surface Interaction, name=IntProp-1; *Friction $(\mu)$; *Surface Behavior, no separation, pressureoverclosure=HARD; *Contact Pair, interaction=IntProp-1, type=SURFACE 
TO SURFACE), and the reaction forces obtained from model 2 are applied (ABAQUS keyword: ${ }^{*}$ Cload). The reaction forces consist of two components (vertical and horizontal) in 2D applications, which have to be applied as load to each node (node-number, component, value of the reaction force) in the Step setup of ABAQUS. For the application of this approach in 3D models, an additional reaction force component in the horizontal direction is obtained, which needs to be applied in the Step setup. The movement along an open fault contact is only driven by the changes in the stress field due to GIA, as the tectonic background stress and overburden pressure are assumed to be constant during the glacial period [e.g. Wu, 1996, Lund et al., 2009].

[6] In the case of a movement along the fault, the displacement and stresses are changed. The displacement and stresses used in the input file of the fault model (model 3) are referred to as $d_{0}$ and $S_{0}$, respectively. In contrast, the output obtained from model 3 with an open fault contact is called $d_{1}$ and $S_{1}$. The difference between $d_{1}$ and $d_{0}$ is the change in the displacement, and the displacement from the output of model 1 at the following time points has to be changed accordingly by this difference. The same is done for the stress tensor, where the difference of $S_{1}$ to $S_{0}$ is extracted and used for all following time points. Only the output for the next time points from model 1 is changed due to the fault movement calculated with model 3 .

[7] If no fault movement occurred, the differences of $d_{1}$ to $d_{0}$ and of $S_{1}$ to $S_{0}$ are zero.

[8] The next time point is used from model 1 , and the displacement $\left(d_{1}-d_{0}\right)$ and stress $\left(S_{1}-S_{0}\right)$ differences from the time point before is added. The fault stability is evaluated again, and if the fault is found to be not stable $(C F S>0)$, a new set of model 2 and 3 is created (see steps [3]- [6]). However, if the fault 
is stable $(C F S<0)$, this set of models is not generated and the next time step is analyzed.

The procedure described above works for any known 2D or 3D GIA model using the FEM, as only the output in the form of displacement and stress is taken. Thus, the GIA model itself is not affected by the fault slip, as no feedback from model 2 and 3 to model 1 exists.

\section{Model setup}

For this preliminary study, a flat 2D earth model is developed, which consists of six layers (Fig. 3) that can be further subdivided in three different parts. The first part is the mechanical lithosphere, which is composed of a $40 \mathrm{~km}$ thick elastic crustal layer, and an elastic lithospheric mantle of $120 \mathrm{~km}$. In total the lithosphere has a thickness of $160 \mathrm{~km}$, which is the same as in general GIA studies dealing with North America [e.g. Peltier, 1984, Steffen et al., 2009]. The second part is the upper mantle, which consists of two layers each with a thickness of $250 \mathrm{~km}$. In contrast to the lithosphere, the upper mantle is a viscoelastic layer with a viscosity of $7 \cdot 10^{20} \mathrm{~Pa} \cdot \mathrm{s}$ [Steffen et al., 2009]. A higher viscosity of $2 \cdot 10^{22} \mathrm{~Pa} \cdot \mathrm{s}$ is assumed for the lower mantle [Steffen et al., 2009], the third part of the earth model. This viscoelastic layer is divided in two sub-layers with the same viscosity, but different material parameters (Fig. 3). The rheological parameters in models 1, 2, and 3 are the same.

Density, gravity, and Young's modulus for all layers (Fig. 3) are determined from the Preliminary Reference Earth Model [PREM; Dziewonski \& Anderson, 1981], and the viscosity values are obtained from general GIA studies constrained by observed data in North America. The sides of the earth model are fixed in the hori- 
zontal direction.

To account for the restoring buoyancy force that drives GIA, so-called Winkler foundations are used in the model (ABAQUS keyword: *Foundation), which are applied along boundaries with density contrasts. The Winkler foundations are calculated from the density contrast along the boundary and the gravity in the lower layer [Wu, 2004].

The earth model of this study includes a fault surface without density contrast. Details about the location and parameters of the fault can be found in the next section. Quadrilateral plane strain elements with 4 nodes (ABAQUS keyword: CPE4) are used for all layers. In the crustal layer, the elements have a side length of approximately $700 \mathrm{~m}$. The size of the elements increases in the following layers and reaches ca. $200 \mathrm{~km}$ in the lowest layer. The mesh consist of 327,666 elements.

\section{Figure 3}

On the top of the earth model, a parabolic ice model (Fig. 3) is applied during glaciation (ABAQUS keyword: *Dload), which simulates the last glacial period in North America. The ice sheet has a maximum thickness of $3500 \mathrm{~m}$ at glacial maximum, and a width of $3000 \mathrm{~km}$. It was shown by Amelung \& Wolf [1994] that flat models without self-gravity can be used for the estimation of deformations inside the ice margin for large ice sheets (e. g. an ice-sheet width of $3000 \mathrm{~km}$ ). To account for the size of the ice sheet and to avoid boundary effects, the model has a width of 40,000 km and a depth of $2891 \mathrm{~km}$ (approximately core-mantle boundary). The initial time is before glaciation, thus no ice is applied on the Earth's surface. The volume of the ice sheet increases linearly for $100 \mathrm{ka}$, and decreases in the following $10 \mathrm{ka}$. For simplicity, the horizontal dimension of the ice sheet is not changed during the glacial period, i. e. there is no migration of the ice margin. 
The new GIA model with a fault, which is a combination of earth and applied ice model, runs from the beginning of loading to $30 \mathrm{ka}$ after glacial maximum. 131 time points are created during the run of the model with a time step of $1 \mathrm{ka}$. The combination of all three models runs in $\sim 36$ hours on a UNIX $2.27 \mathrm{GHz}$ dualcore processor and 3.5 GB of RAM.

\section{The response of a fault due to GIA}

The example model includes a fault from the surface to a depth of $8 \mathrm{~km}$ located at the centre of the ice sheet. The fault dips at $45^{\circ}$, giving a value for $\Theta$ of $45^{\circ}$ for the first time point following equation (2). For the first time point, the maximum principal stress is horizontal, and $\Theta$ is the angle between the normal of the fault to the horizontal direction. Due to the changing stress directions and fault movements, the shear stress increases and the third term in equation (2) is not zero anymore. Therefore, a change in the angle $\Theta$ cannot be neglected; however, the fault angle $\alpha$ stays constant. The fault surface in this model consists of 10 elements on each side of the fault.

The tectonic background stress in northeastern Canada is characterized by a thrusting regime [e.g. Zoback, 1992, Mazzotti \& Townend, 2010, Steffen et al., 2012]. A fault angle of $45^{\circ}$ is chosen as it represents the mean value between the optimally orientated fault angle of $30^{\circ}$ for the thrusting regime and the observed angle of GIFs of about $60^{\circ}$ [Fenton, 1994, Juhlin et al., 2009, Brandes et al., 2012].

The fault is described by a friction coefficient of 0.6 and negligible cohesion along the fault (ABAQUS does not allow the inclusion of a cohesion value as a contact property). For simplicity, zero pore pressure is assumed, which leads to a pore-fluid factor $\lambda_{f}$ of 0 . 
Table 1 gives values for the horizontal background stress and overburden pressure at three depths ( $1 \mathrm{~km}, 10 \mathrm{~km}$, and $15 \mathrm{~km})$ obtained using equations (4) and (3), respectively. The horizontal background stress is the summation of overburden pressure and tectonic background stress, and depends not only on the depth, but also on the angle of the fault $\left(45^{\circ}\right)$ and coefficient of friction (0.6) to keep the fault at frictional equilibrium before the onset of glaciation. Similar stress values at lower depth are obtained for a dry granitic crust [Shimada, 1993].

\section{Table 1}

The response of the GIA model shows the greatest vertical displacement below the maximum load at glacial maximum $(-594 \mathrm{~m})$. At $1900 \mathrm{~km}$ distance from the centre of the model, the peripheral bulge shows the maximum values for the positive vertical displacement $(59 \mathrm{~m})$. At glacial maximum, the axis of tilting, which is indicated by the changeover of the vertical displacement from negative to positive values, occurs at $1600 \mathrm{~km}$, just outside of the ice sheet.

Fig. 4 shows the horizontal rebound stress behaviour at glacial maximum (a), at the end of deglaciation (c), and $10 \mathrm{ka}$ after the end of deglaciation (e), when no fault is included. The vertical and horizontal background stresses are both larger than the GIA stress (Table 1, Fig. 4), and are therefore removed for the visualization. The highest values of horizontal rebound stresses are obtained at glacial maximum (Fig. 4 (a)), but the values decrease only slowly with $21 \mathrm{MPa}$ at glacial maximum to $14 \mathrm{MPa} 10 \mathrm{ka}$ after the end of deglaciation at the surface (Fig. $4(\mathrm{c}, \mathrm{e}))$. In contrast, the vertical loading stress is decreased from $\sim 30 \mathrm{MPa}$ at glacial maximum to $0 \mathrm{MPa}$ at the end of deglaciation and remains zero afterwards.

The total stress determined by the background stress (see Table 1) and the rebound stress vary between a few MPa and several thousands of MPa with increasing depth. 
To account for the stresses in the elements in model 2, reaction forces between $9.6 \cdot 10^{23} \mathrm{~N}$ and $9.6 \cdot 10^{23} \mathrm{~N}$ had to be applied at $2 \mathrm{ka}$ before the end of deglaciation. The highest values were obtained close to the sides of the model at depths of about $2700 \mathrm{~km}$, as in this part the stresses are changing from several MPa to $0 \mathrm{MPa}$ outside the model.

\section{Figure 4}

The fault below the ice-sheet centre is stable for most of the time and becomes unstable $2 \mathrm{ka}$ before the end of deglaciation. The fault stability at this location, which is determined in a subroutine, allows the opening of the fault contact and movement can occur. The fault slips during the earthquake with a maximum of $22 \mathrm{~m}$ at $2 \mathrm{~km}$ depth. Fault slip decreases towards the fault tip and surface, giving a surface fault scarp of 19.74 m (Fig. 5). It was shown by Kim \& Sanderson [2005] that the fault slip decreases towards the tips and is the maximum in the middle between both tips. However, only one fault tip is used here and the other side is open at the surface. One might expect the largest fault slip to be along the surface, but the combination of background stress, which increases with depth, and rebound stress, which decreases with depth, creates larger stresses at $2 \mathrm{~km}$ below the surface. Nevertheless, the total stress increases with depth, but the fixed fault tip prevents further movement, and the slip decreases between $2 \mathrm{~km}$ and the fault tip, which lies at $8 \mathrm{~km}$ depth.

The fault movement releases most of the GIA stress along the fault, and stress is accumulated only at the lower part of the fault as the fault tip is fixed and cannot slip (Fig. 4(d)). These large stresses were found in other studies as well, if a fixed fault tip is used [e.g. Schlagenhauf et al., 2008]. The stress might be released in post-seismic creep, which is not considered in this model. No other parts along 
the fault, excluding the fault tip, are critically stressed again (Fig. 4 (f)). Therefore, no movement occurs at subsequent time points. However, faults at other locations might be activated due to the GIA stress.

The time of fault slip is also visible in the distribution of fault stability $(C F S)$ and normal and shear stress evolution along the fault plane (Fig. 6). At the surface and at $4 \mathrm{~km}$ depth, shear and normal stress decrease by several MPa after the fault slipped. The change in normal and shear stress depends on the magnitude of these stresses before the fault was activated. The increase in $C F S$ before fault activation is similar at all depths, but changes by about $100 \mathrm{MPa}$ at the fault tip and only $7 \mathrm{MPa}$ at the surface. The normal stress at $8 \mathrm{~km}$ depth increases after fault movement, which is not found for other depths and the shear stress. This might be related to the large stress build-up at the tip. After the fault slipped, no change in shear and normal stresses and fault stability is obtained.

\section{Figure 5}

\section{Figure 6}

The distribution of the vertical displacement shows an upward motion of the hanging wall and a downward motion of the footwall (Fig. 7), indicative of a thrusting/reverse earthquake. The vertical displacement ranges between $12.5 \mathrm{~m}$ and $3.1 \mathrm{~m}$, whereas in the far field of the fault the vertical displacement is $0 \mathrm{~m}$. This is in agreement with the analytical solution obtained after Okada [1985] using an elastic half-space, which varies between $12.3 \mathrm{~m}$ and $-3.0 \mathrm{~m}$ (Fig. 7, dashed red line). The analytical solution is obtained using the programme by Beauducel [2012] based on the values of the geometry of the rectangular fault (length, width, depth, strike, dip), the sense of movement (rake value, which is $90^{\circ}$ for a thrust/reverse fault), and the fault slip. The behaviour of the fault movement is similar for mod- 
elled and analytical solution, which verifies our implementation of fault reactivation and slip in the GIA model.

\section{Figure 7}

\section{Conclusions}

In this paper we introduce a new approach to implement slip on a fault in general GIA models, which can be applied to large and small ice sheets. Our technique is applicable to any GIA model using the finite-element method. A cascaded threestep approach is used, in which the first is based on commonly used GIA models. An ice model is applied on top of an earth model, which includes a tied fault contact in the upper crust. The second step uses the results of the first model for each time point. The displacement is applied to change the nodal coordinates, and the stress is changed according to the theory of $\mathrm{Wu}$ [2004] by adding horizontal and vertical background stresses. The stress provides the initial conditions for the elements. The stress values together with the nodal coordinates are not in equilibrium, and both values are not allowed to change. In order to maintain equilibrium, reaction forces are applied. These forces oppose the applied stress and are estimated by fixing all degrees of freedom. In the third step, the fault contact is opened to release the GIA stress. The fault is only driven by the stress changes due to GIA, as horizontal and vertical stresses are assumed to be constant and no velocities are applied at the sides of the model.

Our approach is illustrated using an example with a $45^{\circ}$-dipping fault. Slip of up to $22 \mathrm{~m}$ is modelled to occur at the end of deglaciation, creating a fault scarp of $19.74 \mathrm{~m}$. The fault slip decreases with depth below $2 \mathrm{~km}$. The vertical displacement shows that the earthquake is characterized by a thrusting/reverse mechanism, con- 
sistent with field observations [e.g. Lagerbäck, 1978]. The GIA stress is released with this earthquake, but at the fault tip stress is still concentrated, which may be released in post-seismic creep, but this is not part of the current model.

In the future, changes in the fault parameters (length, $\mu, C$ ) as well as different locations, dipping angles, and the pore-fluid pressure will be tested. Additionally,

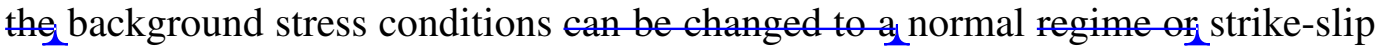
regime. Further possible parameters, which ${ }_{2}$ can be tested, are the magnitude of tectonic background stress, and changes in earth and ice model.

In general, the development of this model algorithm enables the inclusion of more realistic faults within GIA models. This combination is expected to yield a better understanding of glacially induced faults, and what can be expected for regions where deglaciation is ongoing (e.g. Greenland).

\section{Acknowledgments}

We are very grateful for the excellent reviews and numerous valuable suggestions from two anonymous referees and the editor Jef Caers, which have greatly improved this manuscript. Special thanks goes to Björn Lund and Peter Schmidt (both from Uppsala University), and Steffen Abe (RWTH Aachen), for helpful discussions, and to Len Hills (University of Calgary) for suggestions and comments on earlier versions of the manuscript. The research was supported by NSERC Discovery Grants to David W. Eaton and Patrick Wu, and a Research Grant to Rebekka Steffen by the International Association of Mathematical Geosciences. Figures 4, 5, and 7 in this paper are drawn or prepared using the GMT graphics package [Wessel \& Smith, 1998]. 
Abers, G.A. (2009): Slip on shallow-dipping normal faults, Geology, 37, 767-768, doi:10.1130/focus082009.1.

Adams, J. (1989a): Postglacial faulting in eastern Canada: nature, origin and seismic hazard implications, Tectonophysics, 163, 323-331, doi:10.1016/00401951(89)90267-9.

Adams, J. (1989b): Crustal stresses in eastern Canada, In: Gregersen, S. \& Basham, P.W. (eds), Earthquakes at North Atlantic Passive Margins: Neotectonics and Postglacial Rebound, Kluwer, Dordrecht, 289-297.

Adams, J., Wetmiller, R.J., Hasegawa, H.S., Drysdale, J. (1991): The first surface faulting from a historical intraplate earthquake in North America, Nature, 352, 617-619, doi:10.1038/352617a0.

Amelung, F., Wolf, D. (1994): Viscoelastic perturbations of the earth: significance of the incremental gravitational force in models of glacial isostasy, Geophys. J. Int., 117, 864-879, doi:10.1111/j.1365-246X.1994.tb02476.x.

Anderson, E.M. (1951): The dynamics of faulting and dyke formation with applications to Britain, Oliver \& Boyd, Edinburgh, UK, 2nd Edition.

Arvidsson, R. (1996): Fennoscandian Earthquakes: Whole Crustal Rupturing Related to Postglacial Rebound, Science, 274, 744-746, doi:10.1126/science.274.5288.744.

Bängtsson, B., Lund, B. (2008): A comparison between two solution techniques to solve the equations of glacially induced deformation of an elastic Earth, Int. J. Numer. Meth. Engng, 75, 479-502, doi:10.1002/nme.2268.

Beauducel, F. (2012): Okada: Surface deformation due to a finite rectangular source, Published Matlab programme at http://www.mathworks.com/matlabcentral/fileexchange/25982. 
Bonini, M., Sani, F., Antonielli, B. (2012): Basin inversion and contractional reactivation of inherited normal faults: A review based on previous and new experimental models, Tectonophysics, 522-523, 55-88, doi:10.1016/j.tecto.2011.11.014.

Brandes, C., Winsemann, J., Roskosch, J., Meinsen, J., Tanner, D.C., Tsukamoto, S., Frechen, M., Steffen, H., Wu, P. (2012): Activity along the Osning Thrust in Central Europe during the late Weichselian: ice-sheet and lithosphere interactions, Quat. Sci. Rev., 38, 49-62, doi:10.1016/j.quascirev.2012.01.021.

Cathles, L.M. (1975): The Viscosity of the Earth's Mantle, Princeton University Press, Princeton, USA.

Dyke, A.S., Morris, T.F., Green, D.E.C. (1991): Postglacial tectonic and sea level history of the central Canadian Arctic, Geological Survey of Canada Bulletin, 397.

Dziewonski, A.M., Anderson, D.L. (1981): Preliminary reference Earth model, Phys. Earth planet. Inter., 25, 297-356, doi:10.1016/0031-9201(81)90046-7.

Fenton, C. (1994): Postglacial faulting in Eastern Canada, Geological Survey of Canada - Open File, 2774.

Hampel, A., Hetzel, R. (2006): Response of normal faults to glacial-interglacial fluctuations of ice and water masses on Earths surface, J. Geophys. Res., 111, B06406, doi:10.1029/2005JB004124.

Hampel, A., Hetzel, R., Maniatis, G., Karow, T. (2009): Three-dimensional numerical modeling of slip rate variations on normal and thrust fault arrays during ice cap growth and melting, J. Geophys. Res., 114, B08406, doi:10.1029/2008JB006113.

Harris, R.A. (1998): Introduction to special section: Stress triggers, stress shadows, and implications for seismic hazard, J. Geophys. Res., 103, 24347-24358, 
doi:10.1029/98JB01576.

Heidbach, O., Tingay, M., Barth, A., Reinecker, J., Kurfe, D., Mller, B. (2008): The World Stress Map database release 2008, doi:10.1594/GFZ.WSM.Rel2008.

Hetzel, R., Hampel, A. (2005): Slip rate variations on normal faults during glacial-interglacial changes in surface loads, Nature, 435, 81-84, doi:10.1038/nature03562.

Hibbitt, D., Karlsson, B., Sorensen, P. (2011): Getting Started with ABAQUS Version (6.11), Hibbitt, Karlsson \& Sorensen, Inc.

Johnston, A.C. (1987): Suppression of earthquakes by large continental ice sheets, Nature, 330, 467-469, doi:10.1038/330467a0.

Johnston, P., Wu, P., Lambeck, K. (1998): Dependence of horizontal stress magnitude on load dimension in glacial rebound models, Geophys. J. Int., 132, 41-60, doi:10.1046/j.1365-246x.1998.00387.x.

Juhlin, C., Dehghannejad, M., Lund, B., Malehmir, A., Pratt, G. (2009): Reflection seismic imaging of the end-glacial Pärvie Fault system, northern Sweden, $J$. Appl. Geophys., 70, 307-316, doi:10.1016/j.jappgeo.2009.06.004.

Kim, Y.-S., Sanderson, D.J. (2005): The relationship between displacement and length of faults: a review, Ear. Sci. Rev., 68, 317-334, doi:10.1016/j.earscirev.2004.06.003.

Klemann, V., Wolf, D. (1998): Modelling of stresses in the Fennoscandian lithosphere induced by Pleistocene glaciations, Tectonophysics, 294, 291-303, doi:10.1016/S0040-1951(98)00107-3.

Klemann, V., Wu, P., Wolf, D. (2003): Compressible viscoelasticity: stability of solutions for homogeneous plane-Earth models, Geophys. J. Int., 153, 569-585, doi:10.1046/j.1365-246X.2003.01920.x.

Kujansuu, R. (1964): Nuorista siirroksista Lappissa. Summary: Recent faults in 
Lapland, Geologi, 16, 30-36.

Lagerbäck, R. (1978): Neotectonic structures in northern Sweden, Geologiska Föreningen $i$ Stockholm Förhandlingar, 100, 263-269, doi:10.1080/11035897809452533.

Lanaro, F., Öhman, J., Fredriksson, A. (2006). Rock mechanics modelling of rock mass properties - summary of primary data, Swedish Nuclear Fuel and Waste Management Co., Stockholm, Report R-06-15, 68 pp..

Lund, B. (2005): Effects of deglaciation on the crustal stress field and implications for endglacial faulting: A parametric study of simple Earth and ice models, Swedish Nuclear Fuel and Waste Management Co., Stockholm, Technical Report TR-05-04, 68 pp.

Lund, B., Zoback, M.D. (1999): Orientation and magnitude of in situ stress to $6.5 \mathrm{~km}$ depth in the Baltic Shield, Int. J. Rock. Mech. Min. Sci., 36, 169-190, doi:10.1016/S0148-9062(98)00183-1.

Lund, B., Schmidt, P., Hieronymus, C. (2009): Stress evolution and fault stability during the Weichselian glacial cycle, Swedish Nuclear Fuel and Waste Management Co., Stockholm, Technical Report TR-09-15, 101 pp..

Mazotti, S., Townend, J. (2010): State of stress in central and eastern North American seismic zones, Lithosphere, 2, 76-83, doi:10.1130/L65.1.

Ni, Z., Wu, P. (1998): Effects of removing concentric positioning on postglacial vertical displacement in the presence of lateral variation in lithospheric thickness, Geophys. Res. Lett., 25, 3209-3212, doi:10.1029/98GL52326.

Okada, Y. (1985): Surface deformation due to shear and tensile faults in a halfspace, Bull. Seismol. Soc. Am., 75, 1135-1154.

Olesen, O. (1988): The Stuoragurra Fault, evidence of neotectonics in the Precambrian of Finnmark, northern Norway, Norsk Geologisk Tidsskrift, 68, 107-118. 
Peltier, W.R. (1984): The Thickness of the Continental Lithosphere, J. Geophys. Res., 89, B13, 11303, doi:10.1029/JB089iB13p11303.

Peltier, W.R. (2004): Global Glacial Isostasy and the Surface of the Ice-Age Earth: The ICE-5G (VM2) Model and GRACE, Annu. Rev. Earth Planet. Sci., 32, 111149, doi:10.1146/annurev.earth.32.082503.144359.

Quinlan, G. (1984): Postglacial rebound and the focal mechanisms of eastern Canadian earthquakes, Can. J. Earth Sci., 21, 1018-1023, doi:10.1139/e84-106.

Ranalli, G. (1995): Rheology of the Earth, Chapman \& Hall, London, UK, 2nd edition.

Shimada, M. (1993): Lithospheric strength inferred from fracture strength of rocks at high confining pressures and temperatures, Tectonophysics, 217, 55-64, doi:10.1016/0040-1951(93)90202-U.

Schlagenhauf, A., Manighetti, I., Malavieille, J., Dominguez, S. (2008): Incremental growth of normal faults: Insights from a laser-equipped analog experiment, Earth planet. Sci. Lett., 273, 299-311, doi:10.1016/j.eps1.2008.06.042.

Schmidt, P., Lund, B., Hieronymus, C. (2012): Implementation of the glacial rebound prestress advection correction in general-purpose finite element analysis software: Springs versus foundations, Computers \& Geosciences, 40, 97-106, doi:10.1016/j.cageo.2011.07.017.

Slunga, R. (1991): The Baltic shield earthquakes, Tectonophysics, 189, 323-331, doi:10.1016/0040-1951(91)90505-M.

Spada, G., Barletta, V.R., Klemann, V., Riva, R.E.M., Martinec, Z., Gasperini, P., Lund, B., Wolf, D., Vermeersen, L.L.A., King, M.A. (2011): A benchmark study for glacial isostatic adjustment codes, Geophys. J. Int., 185, 106-132, doi:10.1111/j.1365-246X.2011.04952.x.

Steffen, H., Wu, P. (2011): Glacial isostatic adjustment in Fennoscan- 
dia - A review of data and modeling, J. Geodyn., 52(3-4), 169-204, doi:10.1016/j.jog.2011.03.002.

Steffen, H., Müller, J., Denker, H. (2009): Analysis of Mass Variations in Northern Glacial Rebound Areas from GRACE Data, Springer, IAG Symposia Series, ed. M. Sideris, 501-509, doi:10.1007/978-3-540-85426-5_60.

Steffen, R., Eaton, D.W., Wu, P. (2012): Moment tensors, state of stress and their relation to post-glacial rebound in northeastern Canada, Geophys. J. Int., 189, 1741-1752, doi:10.1111/j.1365-246X.2012.05452.x.

Turcotte, D.L., Schubert, G. (2002): Geodynamics, Cambridge University Press, Cambridge, UK, 2nd edition.

Twiss, R.J., Moores, E.M. (2007): Structural Geology, W.H. Freeman and Company, New York, USA, 2nd edition.

van der Wal, W., Wu, P., Wang, H., Sideris, M. (2010): Sea levels and uplift rate from composite rheology in glacial isostatic adjustment modeling, J. Geodyn., 50, 38-48, doi:10.1016/j.jog.2010.01.006.

Wang, H., Wu, P. (2006): Effects of lateral variations in lithospheric thickness and mantle viscosity on glacially induced relative sea levels and long wavelength gravity field in a spherical, self-gravitating Maxwell Earth, Earth planet. Sci. Lett., 249, 368-383, doi:10.1016/j.eps1.2006.07.011.

Wessel, P., Smith, W.H.F. (1998): New, improved version of generic mapping tools released, EOS, Trans. Am. geophys. Un., 79, 579.

Wu, P. (1992): Viscoelastic versus viscous deformation and the advection of prestress, Geophys. J. Int., 108, 136-142, doi:10.1111/j.1365-246X.1992.tb00844.x.

Wu, P. (1996): Changes in orientation of near-surface stress field as constraints to mantle viscosity and horizontal stress differences in Eastern Canada, Geophys. Res. Letters, 23, 2263-2266, doi:10.1029/96GL02149. 
$\mathrm{Wu}, \mathrm{P}$. (1997): Effect of viscosity structure on fault potential and stress orientations in eastern Canada, Geophys. J. Int., 130, 365-382, doi:10.1111/j.1365246X.1997.tb05653.x.

Wu, P. (1999): Modeling Postglacial Sea-Levels with Power Law Rheology and Realistic Ice Model in the Absence of Ambient Tectonic Stress, Geophys. J. Int., 139, 691-702, doi:10.1046/j.1365-246x.1999.00965.x.

Wu, P. (2004): Using commercial Finite element packages for the study of earth deformations, sea levels and the state of stress, Geophys. J. Int., 158, 401-408, doi:10.1111/j.1365-246X.2004.02338.x.

Wu, P. (2009): State-of-the-Science Review of the Stress Field during a Glacial Cycle and Glacial Induced Faulting, Nuclear Waste Management Organization, Technical Report TR-2009-09, 84 pp..

Wu, P., Hasegawa, H.S. (1996a): Induced stresses and fault potential in Eastern Canada due to a disc load: a preliminary analysis, Geophys. J. Int., 125, 415430, doi:10.1111/j.1365-246X.1996.tb00008.x.

Wu, P., Hasegawa, H.S. (1996b): Induced stresses and fault potential in eastern Canada due to a realistic load: a preliminary analysis, Geophys. J. Int., 127, 215229, doi:10.1111/j.1365-246X.1996.tb01546.x.

Wu, P., Steffen, H., Wang, H. (2010): Optimal locations for GPS measurements in North America and northern Europe for constraining Glacial Isostatic Adjustment, Geophys. J. Int., 181, 653-664, doi:10.1111/j.1365-246X.2010.04545.x.

Wu, P., Wang, H., Steffen, H. (2013): The Role of Thermal Effect on Mantle Seismic Anomalies under Laurentia and Fennoscandia from Observations of Glacial Isostatic Adjustment, Geophys. J. Int., 192, 7-17, doi:10.1093/gji/ggs009.

Zoback, M.L. (1992): Stress Field Constraints on Intraplate Seismicity in Eastern North America, J. Geophys. Res., 97, 11761-11782, doi:10.1029/92JB00221. 
721 Zoback, M.D., Townend, J. (2001): Implications of hydrostatic pore pressures 722 and high crustal strength for the deformation of intraplate lithosphere, Tectono723 physics, 336, 19-30, doi:10.1016/S0040-1951(01)00091-9. 
Captions to Figures:

\section{Figure 1:}

Definition of the Mohr circle using the maximum and minimum principal stress magnitudes $\sigma_{1}$ and $\sigma_{3}$, and the definition of the fault stability value $C F S$ depending on the fault angle $\alpha$ (inset). The line of failure is given for a fault without cohesion and with cohesion (red). The coefficient of friction $\mu$, the normal stress $\sigma_{n}$ and the shear stress $\tau$ are used for both equations. The angle $\Theta$ is related to the dipping angle of the fault $\alpha$ by equation (2).

\section{Figure 2:}

Flowchart illustrating the steps of the methodology.

\section{Figure 3:}

Structure of the model used for the implementation of faults. Springs represent foundations used in the model, triangles represent the fixed degree of freedom along the sides of the model, and the red line shows the fault in the crustal layer. The ice sheet follows a parabolic shape without any change in the horizontal dimension (grey body on top of the model). Density $\rho$, Young's modulus $E$, Poisson's ratio $\nu$, viscosity $\eta$, gravity $g$ and thickness values are given for each layer [after Dziewonski \& Anderson, 1981, Steffen et al., 2009]. This model setup is used in all three models. 
Figure 4:

Horizontal stress component of the GIA stress for a model without fault (left) and with fault (right) for three different time points: (a, b) glacial maximum, (c, d) $2 \mathrm{ka}$ before the end of deglaciation (at time of fault movement), (e, f) $10 \mathrm{ka}$ after end of deglaciation. Tectonic background stress and overburden pressure are removed. The black line indicates the fault, and the purple line on top shows the location of the ice sheet during the glacial period. Noise level is due to finite-element structure and interpolation for plotting purposes.

\section{Figure 5:}

Fault slip along the fault at five depths during the last $30 \mathrm{ka}$ of the GIA model. The purple line shows the load applied to the model.

\section{Figure 6:}

Normal stress, shear stress and fault stability $(C F S)$ along the fault surface between $100 \mathrm{ka}$ (maximum glaciation) and $130 \mathrm{ka}$. The values are calculated at three depths along the fault surface: $0.5 \mathrm{~km}$ (surface, blue), $4 \mathrm{~km}$ (mid of the fault, green), and $8 \mathrm{~km}$ (fault tip, red). The purple line shows the load applied to the model.

\section{Figure 7:}

Vertical displacement variation at $108 \mathrm{ka}$ along the surface in 1D obtained from this model (black solid line) and calculated after Okada [1985] using an elastic half-space (dashed red line). The purple line indicates the location of the ice sheet during the glacial period. 
Table 1

Stress magnitudes for overburden pressure and horizontal background stress at several depths. Note that the horizontal background stress in the model is the summation of tectonic background stress and overburden pressure.

\begin{tabular}{|c|c|c|}
\hline Depth & Horizontal background stress & Overburden pressure \\
\hline $1 \mathrm{~km}$ & $128 \mathrm{MPa}$ & $32 \mathrm{MPa}$ \\
$10 \mathrm{~km}$ & $1282 \mathrm{MPa}$ & $320 \mathrm{MPa}$ \\
$15 \mathrm{~km}$ & $1923 \mathrm{MPa}$ & $481 \mathrm{MPa}$ \\
\hline
\end{tabular}




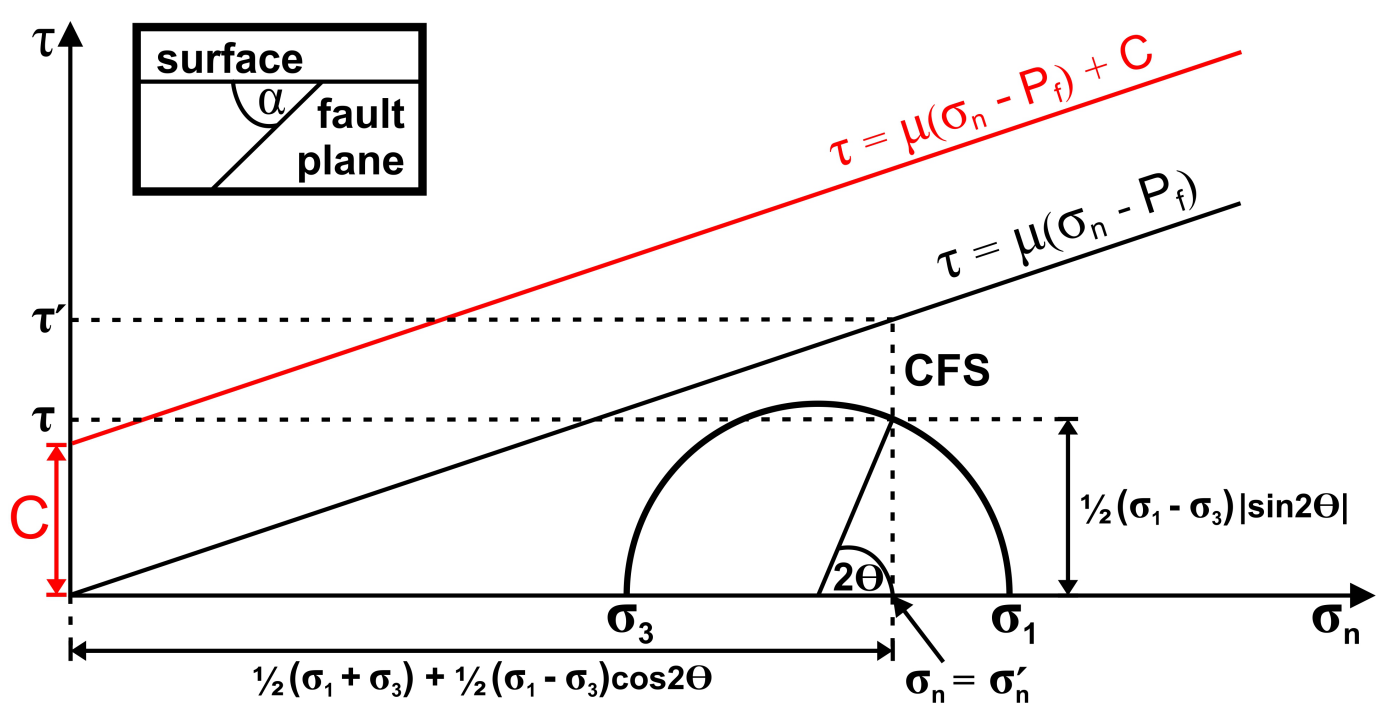

Fig. 1. 


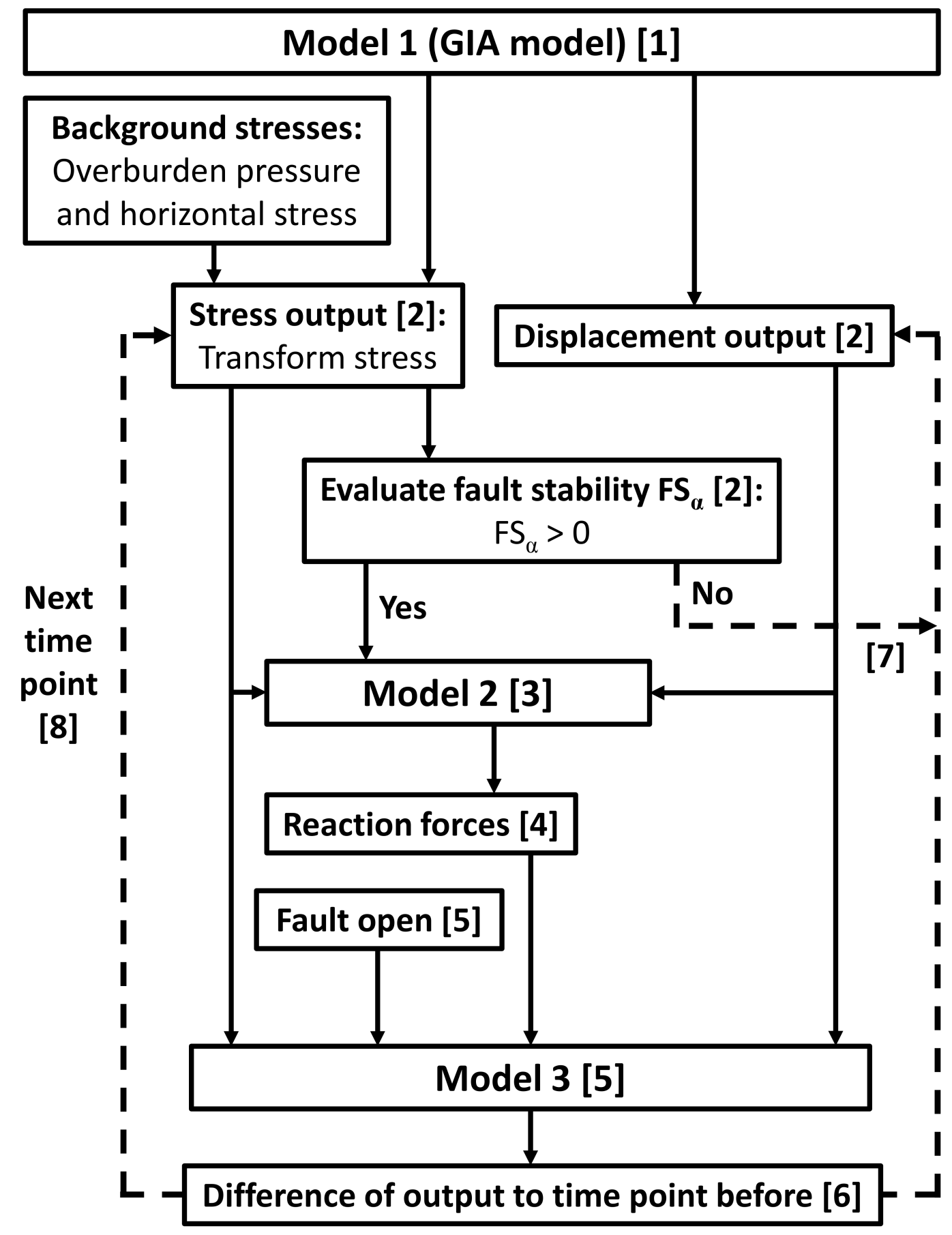

Fig. 2. 


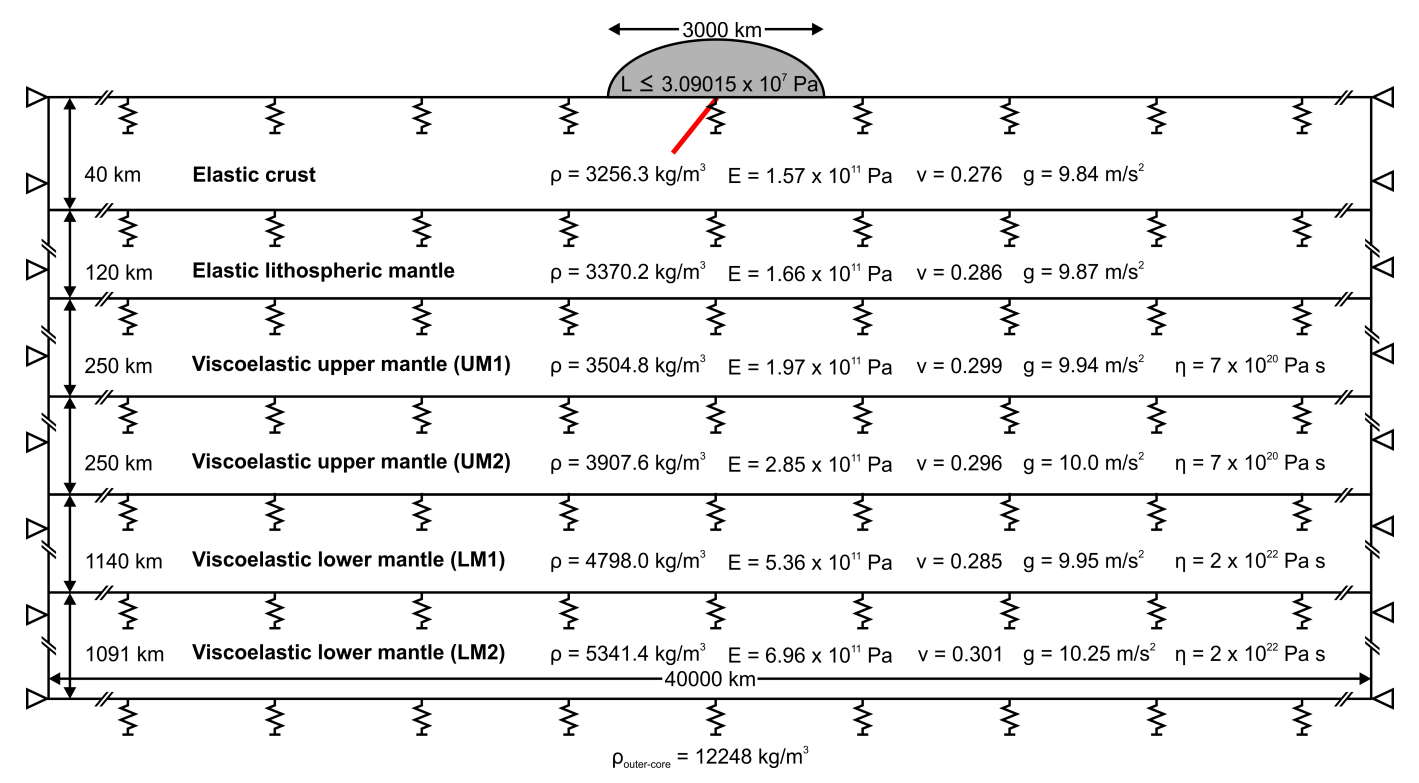

Fig. 3. 
(a)

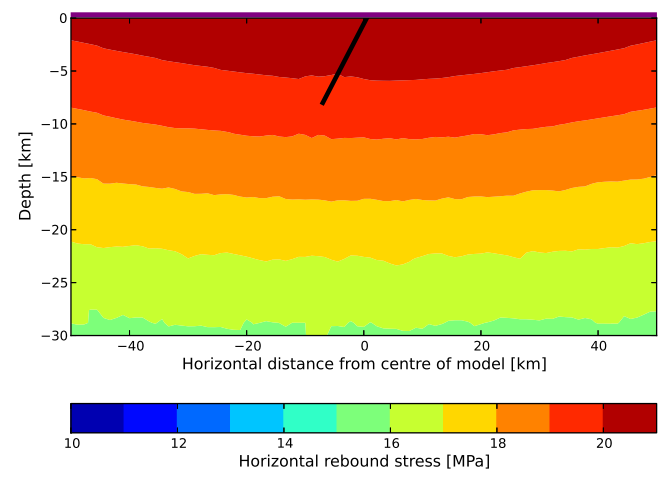

(c)

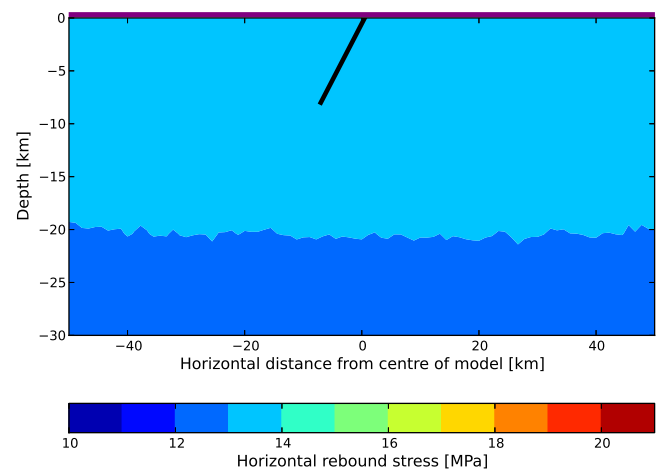

(e)

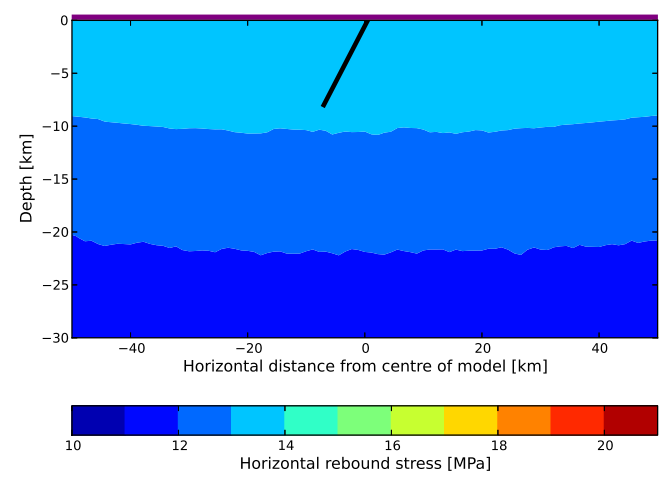

(b)

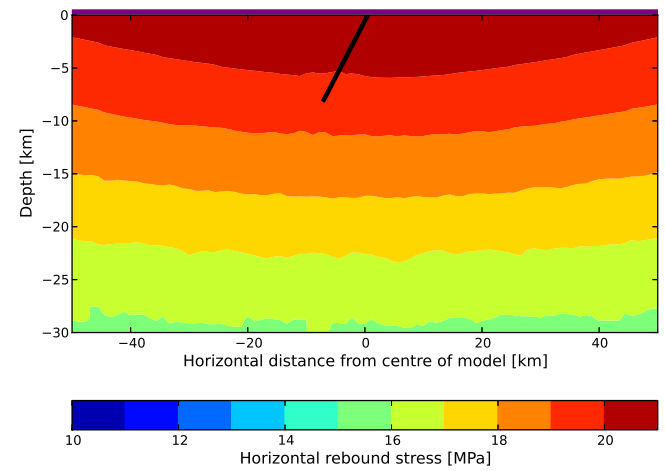

(d)

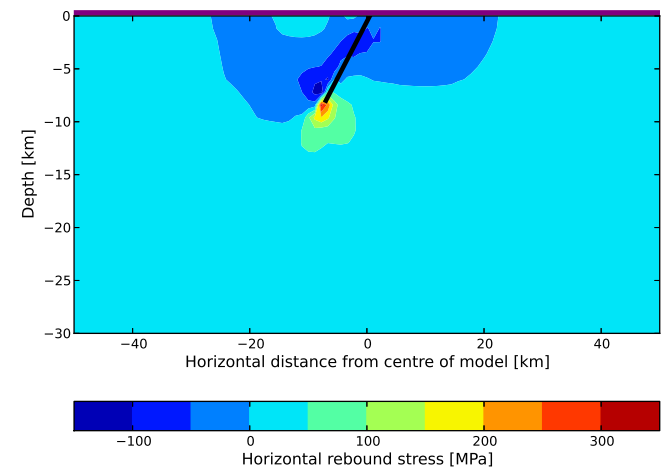

(f)

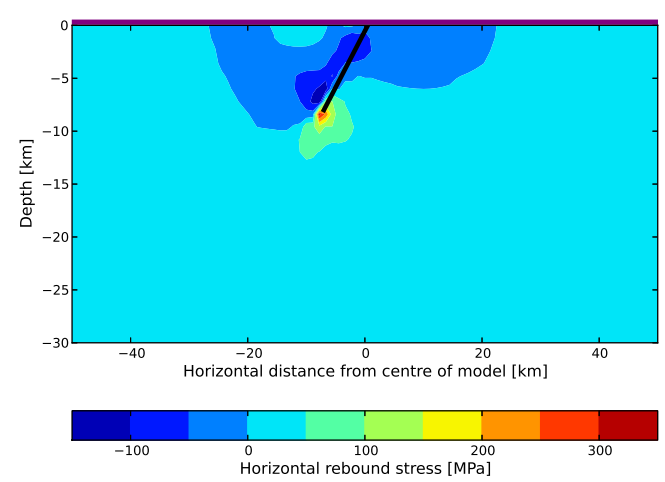

Fig. 4. 


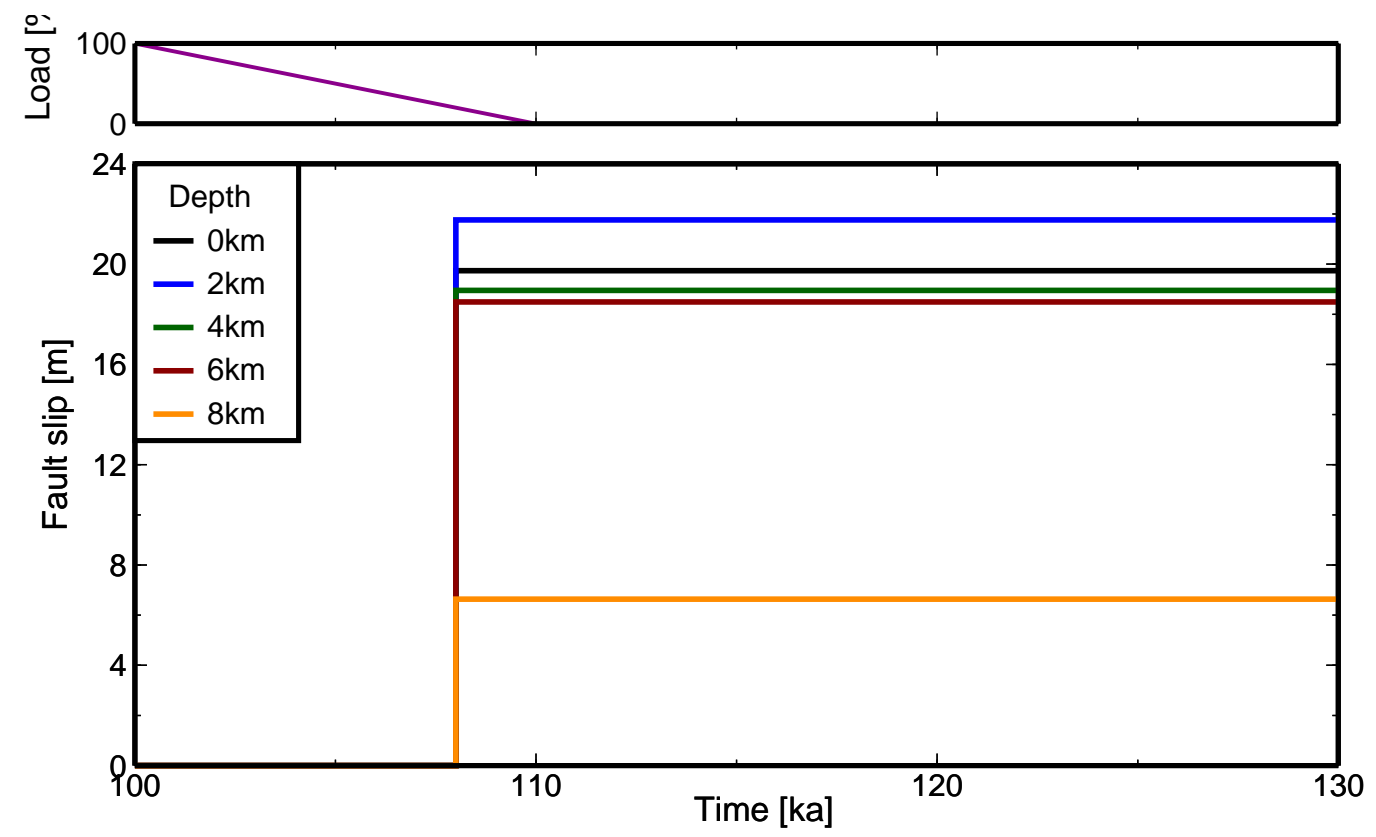

Fig. 5. 


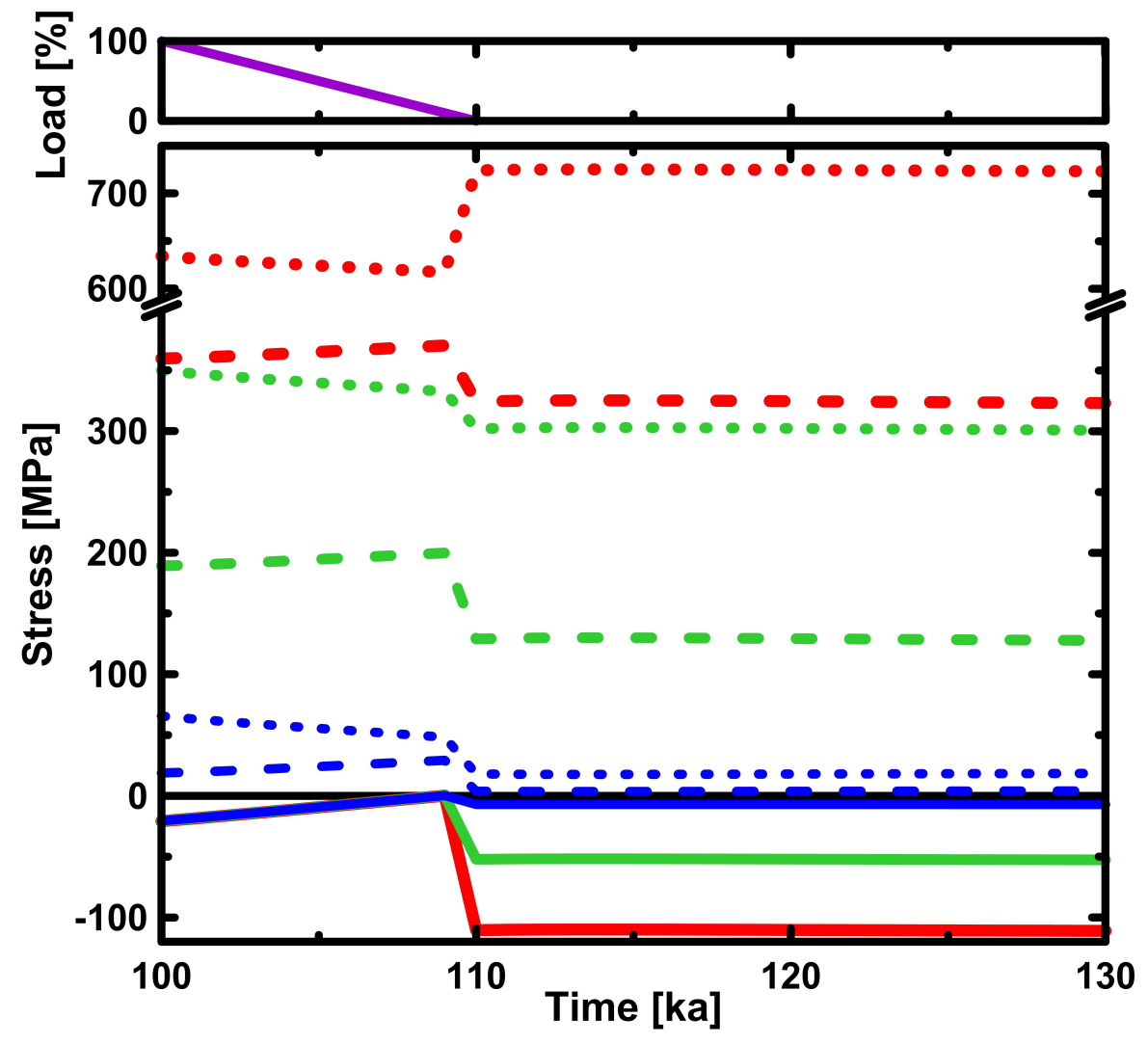

\begin{tabular}{|c|c|c|c|}
\hline $\begin{array}{l}\text { Normal stress } \\
\text { Shear stress }\end{array}$ & $\begin{array}{c}0.5 \mathrm{~km} \\
\ldots \ldots \\
-\quad-\infty\end{array}$ & $\mathbf{4 k m}$ & $8 \mathrm{~km}$ \\
\hline CFS & & 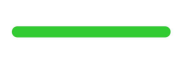 & \\
\hline
\end{tabular}

Fig. 6 . 


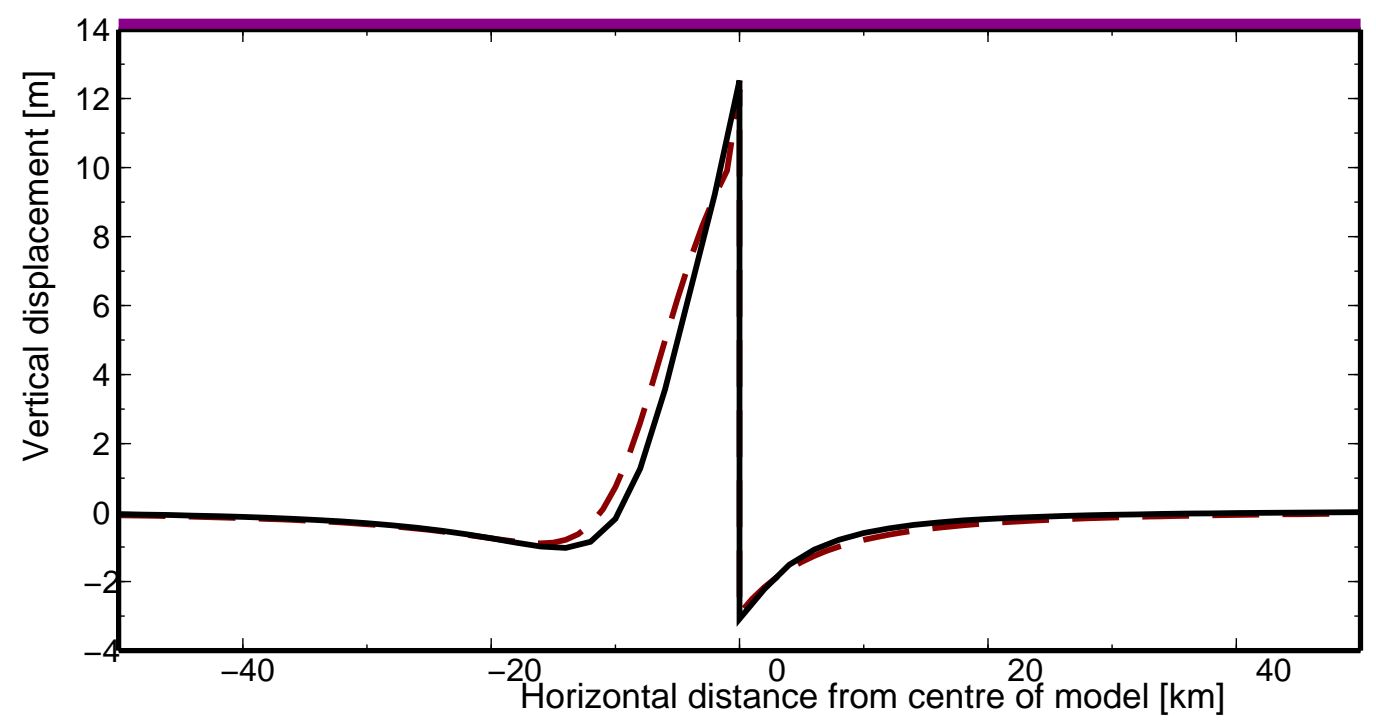

Fig. 7. 